\title{
The Periodontopathic Bacterium Fusobacterium nucleatum Induced Proinflammatory Cytokine Production by Human Respiratory Epithelial Cell Lines and in the Lower Respiratory Organs in Mice
}

\author{
Mayumi Hayata ${ }^{a, b}$ Norihisa Watanabe ${ }^{b, c}$ Muneaki Tamura ${ }^{b}$ Noriaki Kamio $^{b}$ \\ Hajime Tanakab Keiko Nodomi ${ }^{b}$ Chihiro Miyab ${ }^{b, d}$ Enri Nakayama ${ }^{a}$ \\ Koichiro Ueda ${ }^{a}$ Yorimasa Ogata ${ }^{\mathrm{e}}$ Kenichi Imai ${ }^{\mathrm{b}}$ \\ aDepartment of Dysphagia Rehabilitation, Nihon University School of Dentistry, Chiyoda-ku, Tokyo, \\ Japan, bDepartment of Microbiology, Nihon University School of Dentistry, Chiyoda-ku, Tokyo, Japan, \\ 'Department of Periodontology, Nihon University School of Dentistry, Chiyoda-ku, Tokyo, Japan, \\ 'Department of Oral and Maxillofacial Surgery, Nihon University School of Dentistry, Chiyoda-ku, \\ Tokyo, Japan, eDepartment of Periodontology, Nihon University School of Dentistry at Matsudo, Chiba, \\ Japan
}

\section{Key Words}

Chronic periodontitis - Fusobacterium nucleatum • Chronic obstructive pulmonary disease • Proinflammatory cytokines

\footnotetext{
Abstract

Background/Aims: The most prevalent infectious disease, chronic periodontitis which leads to alveolar bone destruction and subsequent tooth loss, develops due to proinflammatory cytokine production induced by periodontopathic bacteria. Chronic obstructive pulmonary disease (COPD), a non-infectious disease, is the third leading cause of death globally. This condition exacerbates frequently, and which is attributable to proinflammatory cytokine production induced by infection by respiratory microorganisms such as Streptococcus pneumoniae. Although a positive association has recently been revealed between chronic periodontitis and COPD, how periodontitis contributes to the pathogenesis of COPD remains unclear. Therefore, we hypothesized that some periodontopathic bacteria are involved in the exacerbation of COPD through the induction of proinflammatory cytokine production by respiratory epithelial cells. In this connection, COPD develops in the airways; however, because most periodontopathic bacteria are anaerobic, they are unlikely to exhibit stable virulence in the lower respiratory organs in humans. Hence, we aimed to elucidate whether

\begin{tabular}{ll}
\hline Kenichi Imai & Department of Microbiology, Nihon University School of Dentistry \\
$1-8-13$, Kanda-Surugadai, Chiyoda-ku, Tokyo 101-8310 (Japan) & Tel. +81-3-3219-8115, Fax +81-3-3219-8317, E-Mail imai.kenichi@nihon-u.ac.jp
\end{tabular}
}




\section{Cellular Physiology Cell Physiol Biochem 2019;53:49-61 \\ \begin{tabular}{ll|l} 
& DOl: 10.33594/000000120 & \\
and Biochemistry 2019 The Author(s). Published by \\
Published online: 7 June 2019 & Cell Physiol Biochem Press GmbH\&Co. KG
\end{tabular} \\ Hayata et al.: F. nucleatum is a Proinflammatory Stimulus to Human Respiratory Epithelial \\ Cells}

exposure to heat-inactivated periodontopathic bacteria induces proinflammatory cytokine production by several human respiratory epithelial cell lines and in the lower respiratory organs and serum in mice. Methods: Real-time polymerase chain reaction and enzyme-linked immunosorbent assay (ELISA) were used to investigate in vitro induction by heat-inactivated periodontopathic bacteria and S. pneumoniae for mRNA expression and protein production of interleukin (IL)-8 and IL-6 by human respiratory epithelial cell lines. ELISA was also used to determine in vivo induction of cytokine production in the lower respiratory organs and serum of intratracheally heat-inactivated Fusobacterium nucleatum-inoculated mice. Results: Some, but not all, periodontopathic bacteria, especially $F$. nucleatum, strongly induced IL-8 and IL- 6 production by BEAS-2B bronchial epithelial cells. In addition, $F$. nucleatum induced IL- 8 production by A549 alveolar epithelial cells as well as IL-8 and IL- 6 production by Detroit 562 pharyngeal epithelial cells. Furthermore, F. nucleatum induced considerably higher cytokine production than S. pneumoniae. This was also observed in the entire lower respiratory organs and serum in mice. Conclusion: Exposure to increased number of $F$. nucleatum potentially induces proinflammatory cytokine production by human bronchial and pharyngeal epithelial cells, which may trigger exacerbation of COPD.

(C) 2019 The Author(s). Published by Cell Physiol Biochem Press GmbH\&Co. KG

\section{Introduction}

Periodontitis, one of the most prevalent diseases worldwide, is a polymicrobial infection and multifactorial disease, but it is simply characterized by chronic inflammation in the periodontium [1, 2]. If left untreated, this condition leads to alveolar bone destruction and subsequently results in tooth loss, during which major periodontopathic bacteria, such as Porphyromonas gingivalis and Fusobacterium nucleatum, are known to be involved in the induction of proinflammatory cytokine production $[1,2]$. Moreover, it may result in systemic complications, such as pre-term birth, diabetes, and cardiovascular diseases [1, 2]. Additionally, we have previously reported that $P$. gingivalis and $F$. nucleatum induced the reactivation of latent viruses, namely human immunodeficiency virus and Epstein-Barr virus $[3,4]$.

Chronic obstructive pulmonary disease (COPD) is an obstructive respiratory disease characterized by chronic inflammation in the lower respiratory tract and emphysema, which is classified as a non-infectious disease with a global prevalence of approximately $10 \%$ among individuals aged $>40$ years [5]. It is also characterized by progression in relation to the repetition of its exacerbation [5]. Therefore, COPD exacerbations have been of major importance because of their prolonged detrimental effects on patients and the resulting high healthcare costs. These exacerbations are represented by increased number of inflammatory cells including neutrophils, elevated levels of proinflammatory cytokines including chemokines, and higher levels of proteases in the respiratory tract [5, 6]. Among host-microbe interactions, a cross-relationship between COPD exacerbations and infection by respiratory bacteria, such as Streptococcus pneumoniae and Haemophilus influenzae, has been extensively delineated [6, 7]. These bacteria have been detected in clinical specimens, such as bronchoalveolar lavage fluid (BALF) and sputum, obtained from patients with COPD $[6,7]$. They induce the production of several proinflammatory cytokines by respiratory epithelial cells, including interleukin (IL)-8 and IL-6, which in turn attracts neutrophils and mediates their degranulation [5-7]. Thus, these respiratory bacteria amplify inflammation in respiratory epithelial cells and activate macrophages, resulting in the subsequent destruction of normal tissues. In this regard, these cytokines detected in the BALF, sputum, or exhaled breath condensates of patients with COPD are also responsible for COPD exacerbation owing to their proinflammatory nature [6, 8-11].

Evidence accumulated over the past decade indicates that chronic periodontitis aggravated by poor oral hygiene is a risk factor for COPD [12-15]. A recent meta-analysis of 14 studies involving 3988 patients with COPD has revealed a significant association between chronic periodontitis and COPD [12]. For example, alveolar bone loss, a typical symptom 


\section{Cellular Physiology Cell Physiol Biochem 2019;53:49-61 \begin{tabular}{ll|l} 
and Biochemistry $10.33594 / 000000120$ & Dublished online: 7 June 2019 & $\begin{array}{l}\text { C) } 2019 \text { The Author(s). Published by } \\
\text { Cell Physiol Biochem Press GmbH\&Co. KG }\end{array}$
\end{tabular} \\ Hayata et al.: F. nucleatum is a Proinflammatory Stimulus to Human Respiratory Epithelial Cells}

of chronic periodontitis, is associated with an increased risk of COPD [14, 15]. In addition, periodontopathic bacteria are frequently detected in clinical specimens from patients with COPD [16-19]. Furthermore, periodontal interventions significantly reduce the frequency of COPD exacerbations $[20,21]$. Additionally, on an average, an individual generates and ingests up to $1.5 \mathrm{l}$ of saliva per day, and saliva contains an enormous number of bacteria released from the mouth [22]. Approximately half of all healthy adults experience salivary aspiration during sleep [23]. Further, in patients with COPD, the risk of aspiration has increased because these patients have reduced laryngopharyngeal sensitivity [24]. Thus, these observations suggest that periodontopathic bacteria present in saliva are aspirated through the pharynx into the lower respiratory tract, thereby triggering COPD exacerbations. However, how periodontopathic bacteria contribute to COPD exacerbations remains unexamined.

As the majority of periodontopathic bacteria are anaerobic, they are unlikely to exhibit stable virulence in the respiratory tract. In addition, it is unclear how long these bacteria survive in vitro and in vivo. Therefore, we examined whether some periodontopathic bacteria induced proinflammatory cytokine production by several human respiratory epithelial cells merely on exposure to heat-inactivated bacteria.

In the present study, for the first time, we present a causal association between periodontopathic bacteria, especially $F$ nucleatum, and the inducible production of proinflammatory cytokines, namely IL-8 and IL-6, both of which are surrogate clinical mediators of COPD exacerbations, from human bronchial and pharyngeal epithelial cells and in the lower respiratory organs and serum in mice.

\section{Materials and Methods}

\section{Cell culture}

Human bronchial (BEAS-2B), pharyngeal (Detroit 562), and alveolar (A549) epithelial cells were purchased from ATCC (Manassas, VA, USA) and maintained at $37^{\circ} \mathrm{C}$ in Dulbecco's modified Eagle's medium (Sigma-Aldrich, St. Louis, MO, USA) containing 10\% heat-inactivated fetal bovine serum (Thermo Fisher Scientific Inc., Rockford, IL, USA), penicillin $(100 \mathrm{U} / \mathrm{ml})$, and streptomycin $(100 \mathrm{mg} / \mathrm{ml})$ as described previously.

\section{Bacterial culture and sample adjustment}

F. nucleatum ATCC 25586, P. gingivalis ATCC 33277, Prevotella intermedia ATCC 25611, Aggregatibacter actinomycetemcomitans Y4, Tannerella forsythia JCM 10827, Treponema denticola ATCC 35405, S. mitis JCM 12971, S. salivarius JCM 5707, and S. pneumoniae ATCC 49619 were used throughout this study. S. mitis, S. salivarius, and S. pneumoniae were cultured in brain heart infusion broth (BHIB; Becton, Dickinson and Company, Sparks, MD, USA). F. nucleatum, P. gingivalis, P. intermedia, and A. actinomycetemcomitans were cultured in BHIB supplemented with $5 \mu \mathrm{g} / \mathrm{ml}$ hemin and $0.5 \mu \mathrm{g} / \mathrm{ml}$ menadione. T. forsythia was cultured in BHIB supplemented with $5 \mu \mathrm{g} / \mathrm{ml}$ hemin, $0.5 \mu \mathrm{g} / \mathrm{ml}$ menadione, $10 \mu \mathrm{g} / \mathrm{ml} N$-acetylmuramic acid, and $5 \%$ fetal calf serum. T. denticola was cultured in new oral spirochete broth as previously described [4, 25].

All cultures were incubated at $37^{\circ} \mathrm{C}$ for $24-72 \mathrm{~h}$ and grown in an anaerobic chamber (Te-Her Anaerobox, Hirasawa Co. Ltd., Tokyo, Japan) under an aerobic condition of $10 \% \mathrm{H}_{2}, 10 \% \mathrm{CO}_{2}$, and $80 \% \mathrm{~N}_{2}$. Subsequently, culture supernatants were obtained via centrifugation at $7000 \times g$ for $10 \mathrm{~min}$ at $4^{\circ} \mathrm{C}$ and then filtrated through a $0.22-\mu \mathrm{m}$ pore filter membrane. In parallel, the bacterial cell density was adjusted to 1.0 $\times 10^{10} \mathrm{CFU} / \mathrm{ml}$, and the bacterial suspension was heat-inactivated at $60^{\circ} \mathrm{C}$ for $1 \mathrm{~h}$ and then stored at $-80^{\circ} \mathrm{C}$ until use.

IRNA preparation and real-time polymerase chain reaction (PCR)

The experimental procedures for RNA purification and real-time PCR were performed as previously described [26]. Briefly, BEAS-2B cells were washed once with ice-cold phosphate-buffered saline (PBS) and homogenized using a QIAshredder (QIAGEN, Alameda, CA, USA), while total RNA was purified using an RNeasy Mini Kit (QIAGEN). For cDNA synthesis, total RNA $(1 \mu \mathrm{g})$ was reverse transcribed using an RNA PCR kit (PrimeScript; Takara Bio, Shiga, Japan). The resulting cDNA mixture was subjected to real-time PCR 


\section{Cellular Physiology Cell Physiol Biochem 2019;53:49-61 \\ \begin{tabular}{ll|l} 
and Biol: $10.33594 / 000000120$ & & C 2019 The Author(s). Published by \\
Cell Physiol Biochem Press GmbH\&Co. KG
\end{tabular} \\ Hayata et al.: F. nucleatum is a Proinflammatory Stimulus to Human Respiratory Epithelial \\ Cells}

analysis using SYBR Premix Ex Taq solution (Takara Bio) containing $5 \mu \mathrm{M}$ sense and antisense primers. The primer sequences used for the amplification of each gene were as follows: IL-8, forward (5-CTT GTC ATT GCC AGC TGT GT-3) and reverse (5-TGA CTG TGG AGT TTT GGC TG-3); IL-6, forward (5-TTC GGT CCA GTT GCC TTC TC-3) and reverse (5-GAG GTG AGT GGC TGT CTG TG-3); and glyceraldehyde-3-phosphate dehydrogenase (GAPDH), forward (5-ACC AGC CCC AGC AAG AGC ACA AG-3) and reverse (5-TTC AAG GGG TCT ACA TGG CAA CTG-3). PCR assays were performed using a TP-800 Thermal Cycler Dice Real-Time System (Takara Bio) and analyzed using the software provided by the device manufacturer. The thermal cycling conditions were 40 cycles at $95^{\circ} \mathrm{C}$ for $5 \mathrm{~s}, 60^{\circ} \mathrm{C}$ for $30 \mathrm{~s}$, and $72^{\circ} \mathrm{C}$ for $1 \mathrm{~min}$. All real-time PCR experiments were performed in triplicates, and the specificity of each product was verified via a melting curve analysis. The calculated gene expression levels were normalized to GAPDH mRNA levels.

\section{Cytokine measurements}

The IL-8 and IL-6 concentrations in the cell culture supernatants were measured using an ELISA kit (R\&D Systems, Minneapolis, MN, USA), according to the procedures recommended by the manufacturer. All experiments were performed in triplicate and data are presented as the mean \pm standard deviation.

\section{Animals and inoculation procedures}

All animal experiments were conducted in accordance with the Regulations and Guidelines on Scientific and Ethical Care and Use of Laboratory Animals of the Science Council of Japan, enforced on June 1, 2006. The study protocol was approved by the Institutional Animal Care and Committee of Nihon University School of Dentistry (Permit Number: AP16D047). Specific pathogen-free male C57BL/6JJcl mice aged 7 weeks were obtained from CLEA Japan, Inc. (Tokyo, Japan). The mice were housed under standard conditions within the animal care facility at the Nihon University School of Dentistry, Tokyo, Japan. All mice were anesthetized with aspirating isoflurane and inoculated with bacteria intratracheally. The final bacterial loads of $F$. nucleatum and $S$. pneumoniae were $1 \times 10^{8} \mathrm{CFU} /$ mouse suspended in atol volume of $50 \mu \mathrm{l}$ of PBS. PBS-treated mice (control) and bacteria-treated mice were housed in separate cages for $2 \mathrm{~h}$. The Nihon University of Animal Care and Use Committee approved the protocol.

\section{Sample collection from mice and cytokine quantitation}

Mice were sacrificed after a 2-h exposure to bacteria. Then, whole blood was collected from the abdominal aorta, and the trachea and lungs were surgically removed. Serum was separated by centrifuging blood samples and stored at $-80^{\circ} \mathrm{C}$ until use. Tracheal and lung tissues were homogenized in radioimmunoprecipitation assay buffer using a BioMasher (Nippi, Tokyo, Japan) and centrifuged. The supernatants were collected and stored at $-80^{\circ} \mathrm{C}$ until use. Production of the inflammatory cytokines KC and IL-6 in the serum and tissue homogenates was determined using ELISA kits (R\&D Systems). The level of each cytokine was normalized to the amount of total protein.

\section{Results}

Effects of human oral bacteria on proinflammatory cytokine production by a human bronchial epithelial cell line

Among more than 700 species of human oral bacteria, a few gram-negative anaerobes have been linked to human chronic periodontitis. First, we investigated the effects of human oral bacteria on IL-8 and IL- 6 production by BEAS-2B human bronchial epithelial cells. BEAS2B cells were incubated for $12 \mathrm{~h}$ with and without the heat-inactivated bacterial suspension, and the protein levels of both cytokines secreted into the supernatants were then measured using ELISA. As shown in Fig. 1, human periodontopathic bacteria, such as $P$. gingivalis, $F$. nucleatum, T. forsythia, $P$. intermedia, and A. actinomycetemcomitans, substantially induced IL-8 and IL- 6 production by BEAS-2B cells. In particular, F. nucleatum induced the release of extremely high concentrations of both cytokines. Conversely, T. denticola negligibly induced cytokine production. In parallel, two oral streptococci predominant in the human saliva, namely $S$. salivarius and $S$. mitis, failed to elicit cytokine production. 


\section{Cellular Physiology Cell Physiol Biochem 2019;53:49-61 \begin{tabular}{ll|l} 
aOl: 10.33594/000000120 & ( ) 2019 The Author(s). Published by \\
Cell Physiol Biochem Press GmbH\&Co. KG
\end{tabular} \\ Hayata et al.: F. nucleatum is a Proinflammatory Stimulus to Human Respiratory Epithelial Cells}

F. nucleatum induced $m R N A$ expression and protein production of $I L-8$ and IL-6 by human bronchial epithelial cell line

As only $F$ nucleatum induced extremely high proinflammatory cytokine production among heat-inactivated periodontopathic bacteria and as it is predominant in periodontitis lesions and is found in clinical specimens obtained from patients with COPD [17-19], realtime PCR analysis was performed to investigate the effects of $F$. nucleatum on the mRNA expression of these cytokines in BEAS-2B cells. As shown in Fig. 2a, $F$ nucleatum markedly upregulated IL-8 and IL-6 mRNA levels after a 1-h exposure, with peaking after a 24-h exposure $(636 \pm 172$ - and $217 \pm 35$-fold, respectively). Fig. $2 \mathrm{~b}$ demonstrates that F. nucleatum also markedly induced IL-8 and IL- 6 production between 1- and 24-h exposures. To clarify the cause-and-effect relationship between the number of bacteria and the cytokine expression level, we further examined density dependency using $F$. nucleatum at densities between $1 \times 10^{6}$ and $1 \times 10^{8} \mathrm{CFU} / \mathrm{ml}$. As shown in Fig. $2 \mathrm{c}$ and d, F. nucleatum elicited mRNA expression and production of both cytokines in a density-dependent manner.

Effects of F. nucleatum on $I L-8$ and IL-6 production by human respiratory epithelial cell lines

Next, we examined whether heatinactivated $F$. nucleatum could induce proinflammatory cytokine production in other human respiratory epithelial cell lines, such as A549 alveolar cells and Detroit 562 pharyngeal cells. As shown in Fig. 3a, IL-8 production was induced in A549 cells, whereas IL-6 production was not. Meanwhile, F. nucleatum induced the production of both cytokines by Detroit 562 cells in a density-dependent manner, as shown in Fig. 3b.

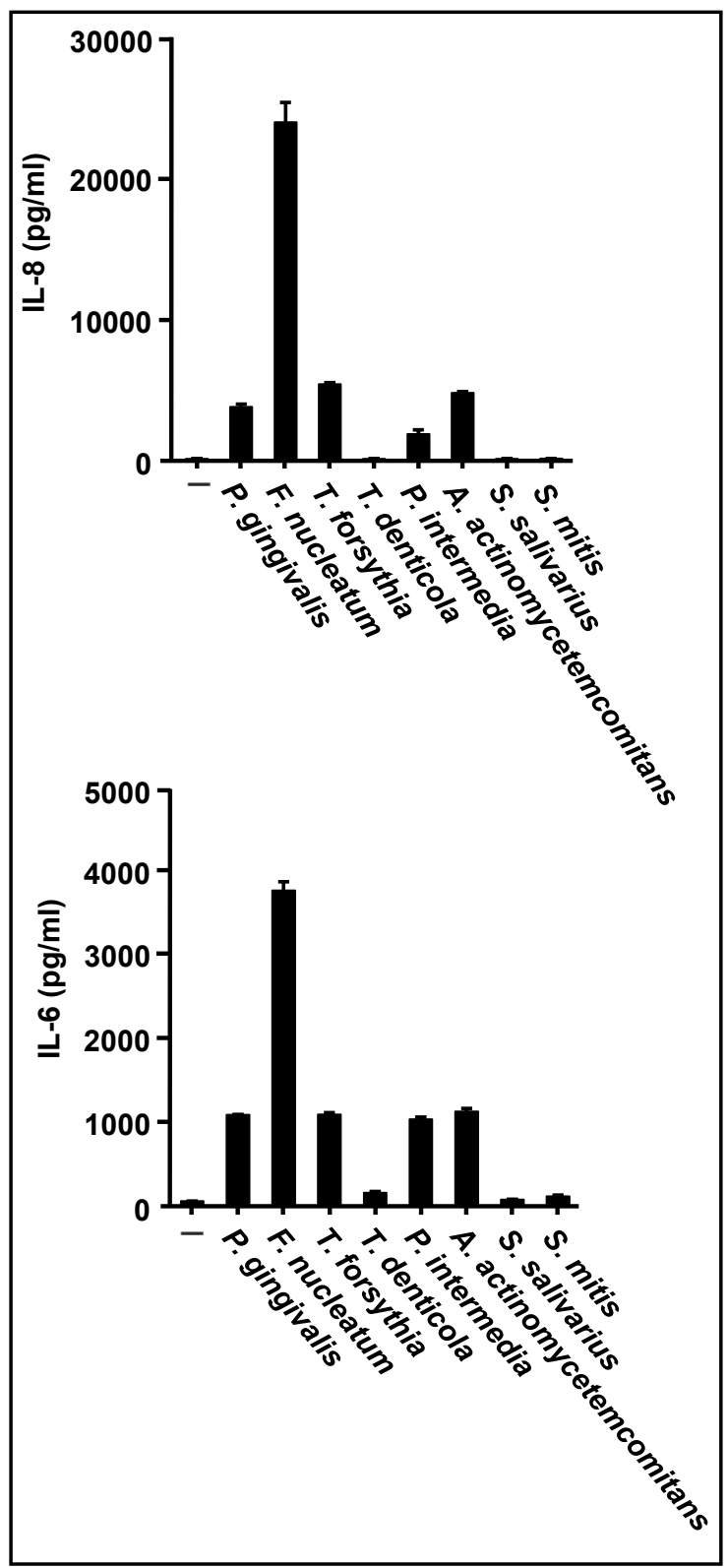

Fig. 1. Effects of human oral bacteria on IL-8 and IL-6 production by human bronchial epithelial cells. BEAS-2B cells were treated with or without indicated heat-inactivated oral bacteria at a bacterial density equivalent to $1 \times 10^{8} \mathrm{CFU} / \mathrm{ml}$ for $12 \mathrm{~h}$, after which IL-8 and IL- 6 protein levels in the cell culture supernatants were determined using ELISA and expressed as $\mathrm{pg} / \mathrm{ml}$. Data are presented as the mean \pm SD. 
Hayata et al.: F. nucleatum is a Proinflammatory Stimulus to Human Respiratory Epithelial

Cells

Fig. 2. Fusobacterium nucleatum-induced mRNA (a, c) and protein (b, d) expression of proinflammatory cytokines by bronchial epithelial cells. BEAS-2B cells were treated with heat-inactivated $F$. nucleatum $\left(1 \times 10^{8}\right.$ $\mathrm{CFU} / \mathrm{ml}$ ) for the indicated times (a, b) and at different bacterial cell densities $\left(1 \times 10^{6}\right.$, $1 \times 10^{7}$, and $1 \times 10^{8}$ $\mathrm{CFU} / \mathrm{ml}$ ) after 3- (c) and 12-h exposures (d). The cells were harvested, and IL-8 and IL- 6 mRNA levels were measured using real-time PCR with specific primers. The mRNA level was normalized to the GAPDH mRNA level and expressed as a fold increase. The IL-8 and IL-6 protein levels were determined using ELISA and expressed as $\mathrm{pg} / \mathrm{ml}$. Data are presented as the mean \pm SD.
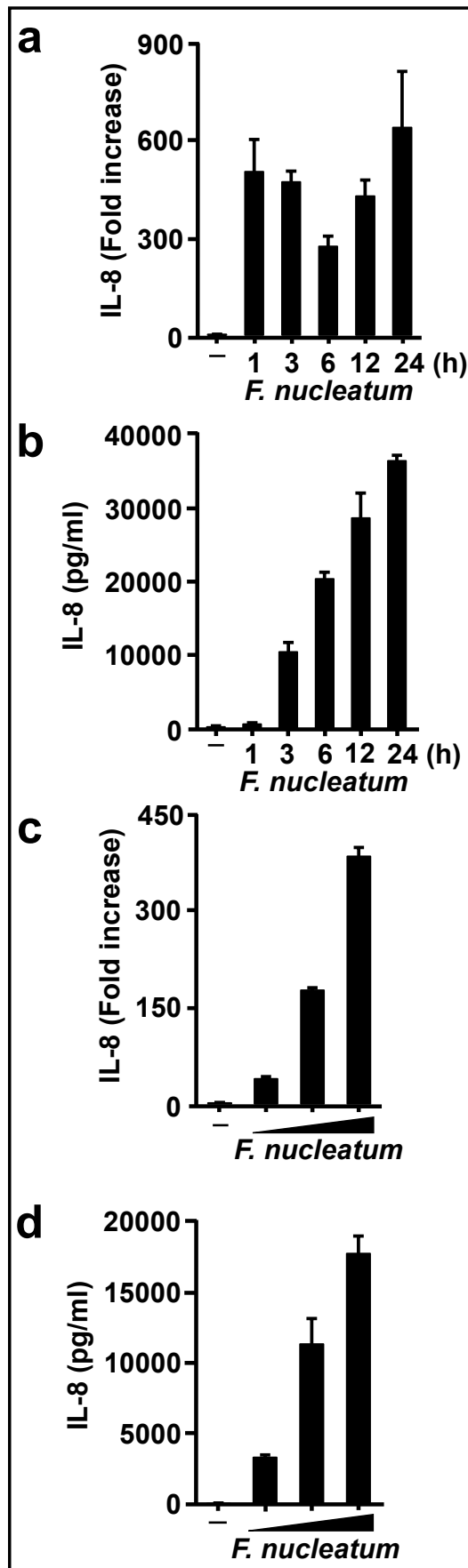
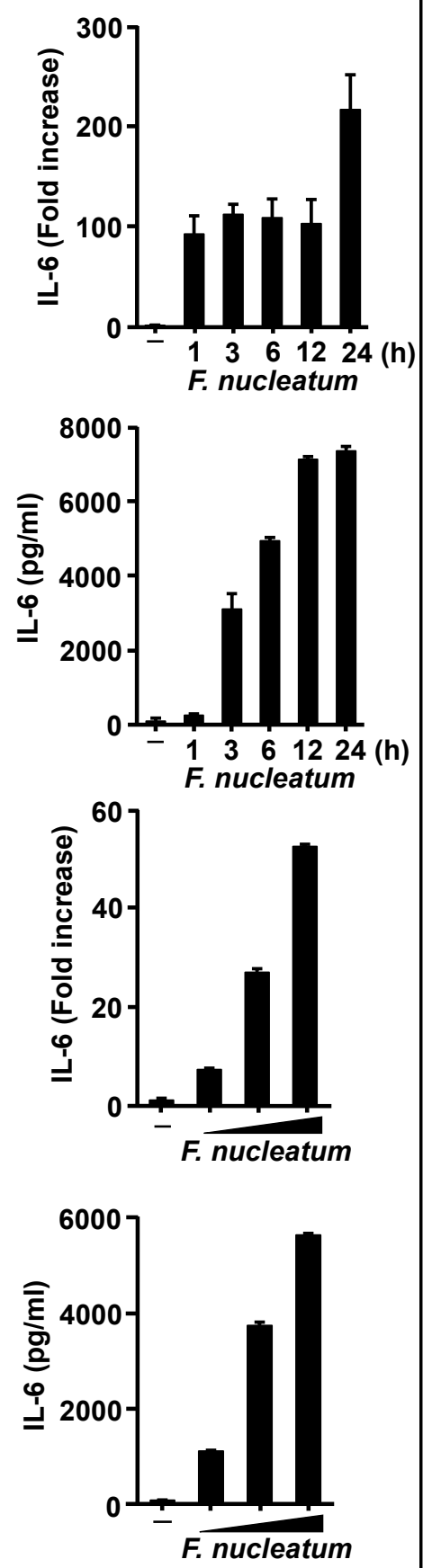

F. nucleatum induced IL-8 and IL-6 production by human respiratory epithelial cell lines more strongly than S. pneumoniae

Because $S$. pneumoniae contributes to COPD exacerbations by inducing the production of proinflammatory cytokines, including IL-8 and IL-6 [5, 7], we compared this induction by $S$. pneumoniae and F. nucleatum in three human respiratory epithelial cell lines. As shown in Fig. 4, S. pneumoniae induced IL-8 production by BEAS-2B, A549, and Detroit 562 cells, albeit at much lower levels than F. nucleatum. A similar induction was also observed for IL-6 production by BEAS-2B and Detroit 562 cells. 
Hayata et al.: F. nucleatum is a Proinflammatory Stimulus to Human Respiratory Epithelial

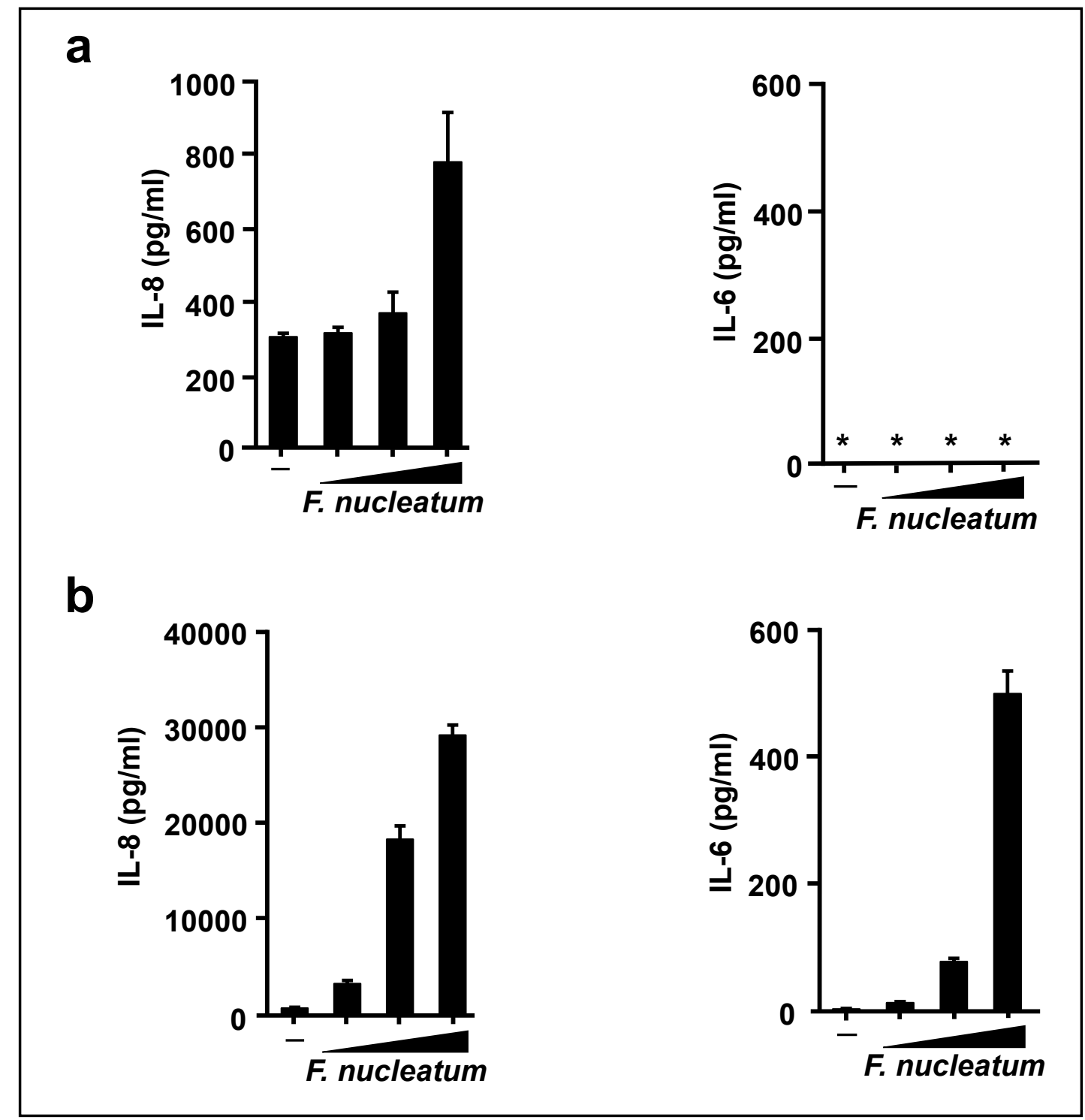

Fig. 3. Effects of Fusobacterium nucleatum on IL-8 and IL-6 production by two respiratory epithelial cell lines. Human alveolar (A549) (a) and pharyngeal (Detroit 562) (b) epithelial cells were incubated with heat-inactivated F. nucleatum at $1 \times 10^{8} \mathrm{CFU} / \mathrm{ml}$ for $12 \mathrm{~h}$. IL-8 and IL-6 protein levels in the cell culture supernatants were determined using ELISA and expressed as $\mathrm{pg} / \mathrm{ml}$. Data are presented as the mean \pm SD. *; a value below the detection limit.

\section{Effects of $F$. nucleatum and S. pneumoniae on KC and IL-6 production in mice}

To compare the effects of $F$. nucleatum and $S$. pneumoniae on in vivo cytokine production, we further investigated the production of KC, an IL-8 homologous neutrophil chemoattractant in mice, as well as that of IL-6 in the presence of heat-inactivated $F$. nucleatum or live $S$. pneumoniae. This experiment was conducted within a short period such as $2 \mathrm{~h}$, during which bacterial infection was not established [27] in the lower respiratory organs in mice. As shown in Fig. 5a, both heat-inactivated and live $S$. pneumoniae appeared to induce KC and IL-6 production in the lungs of mice. However, there were no statistical differences in terms of KC and IL- 6 production between the bacteria-treated and control mice. Conversely, F. nucleatum alone induced the prodigious production of both cytokines, and this finding was consistent with our in vitro results. Remarkably, as shown in Fig. 5b, although the mouse trachea is as short as $1 \mathrm{~cm}$ in length, this tendency was also observed in such a shorter respiratory 


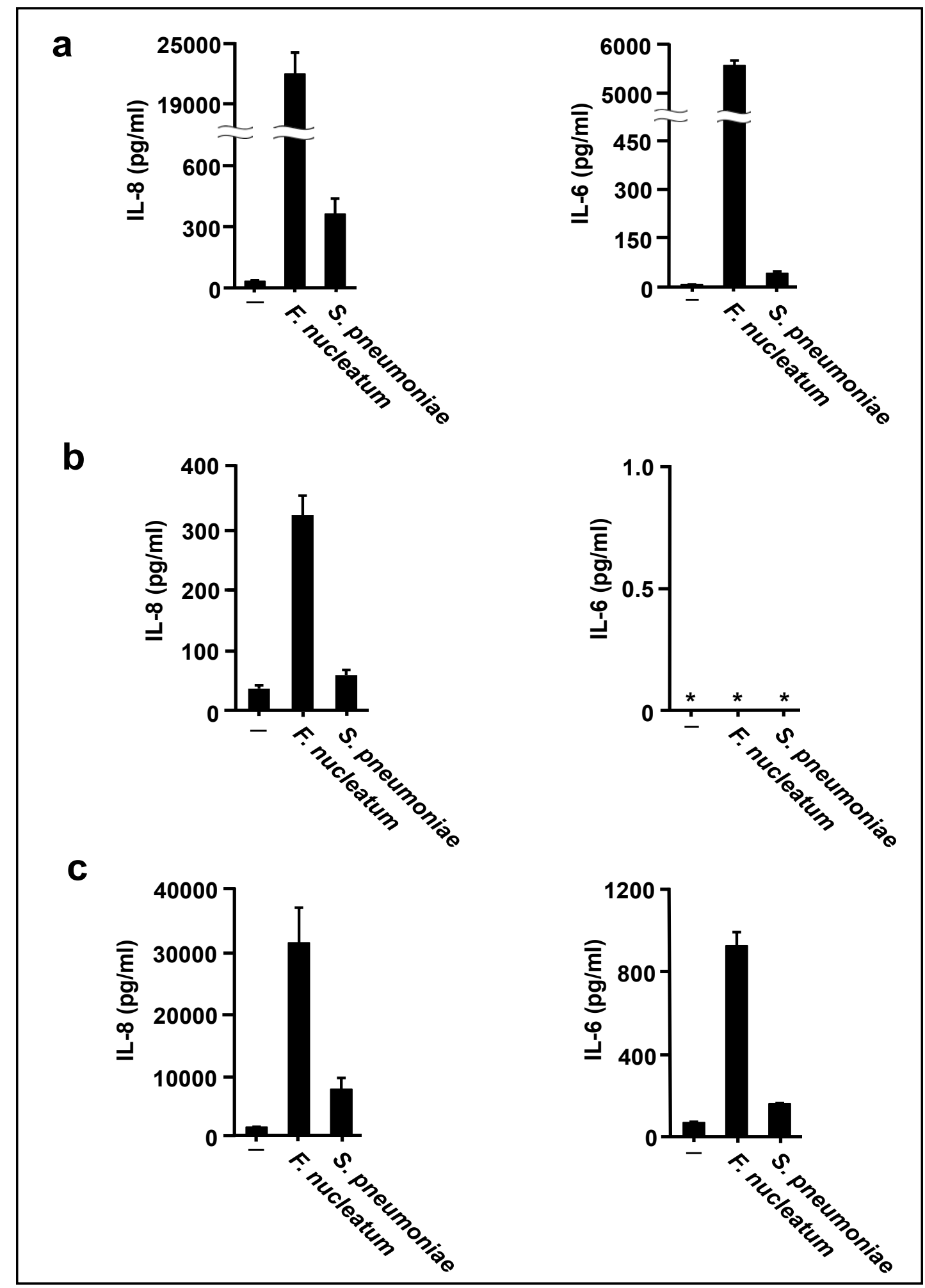

Fig. 4. Comparison of the effects of Fusobacterium nucleatum and Streptococcus pneumoniae on inflammatory cytokine production. BEAS-2B (a), A549 (b), and Detroit 562 (c) cells were treated with heat-inactivated $F$. nucleatum $\left(1 \times 10^{8} \mathrm{CFU} / \mathrm{ml}\right)$ or heat-inactivated $S$. pneumoniae $\left(1 \times 10^{8} \mathrm{CFU} / \mathrm{ml}\right)$ for $12 \mathrm{~h}$. IL-8 and IL- 6 levels in the cell culture supernatants were determined using ELISA and expressed as $\mathrm{pg} / \mathrm{ml}$. Data are presented as the mean \pm SD. *; a value below the detection limit. 
Hayata et al.: F. nucleatum is a Proinflammatory Stimulus to Human Respiratory Epithelial Cells

Fig. 5. Effects of Fusobacterium nucleatum and Streptococcus pneumoniae on the production of proinflammatory cytokines in vivo. Mice $(\mathrm{n}=6)$ were treated with heatinactivated $F$. nucleatum $(1 \times$ $10^{8}$ CFU/mouse), heat-inactivated $S$. pneumoniae $\left(1 \times 10^{8}\right.$ $\mathrm{CFU} /$ mouse), or live S. pneumoniae (1 $\times 10^{8} \mathrm{CFU} /$ mouse) for $2 \mathrm{~h}$. KC and IL-6 protein levels in the lungs (a), trachea (b), and serum (c) were determined using ELISA and expressed as $\mathrm{pg} / \mathrm{mg}$ protein or $\mathrm{pg} / \mathrm{ml}$. Data are presented as the mean \pm SD.

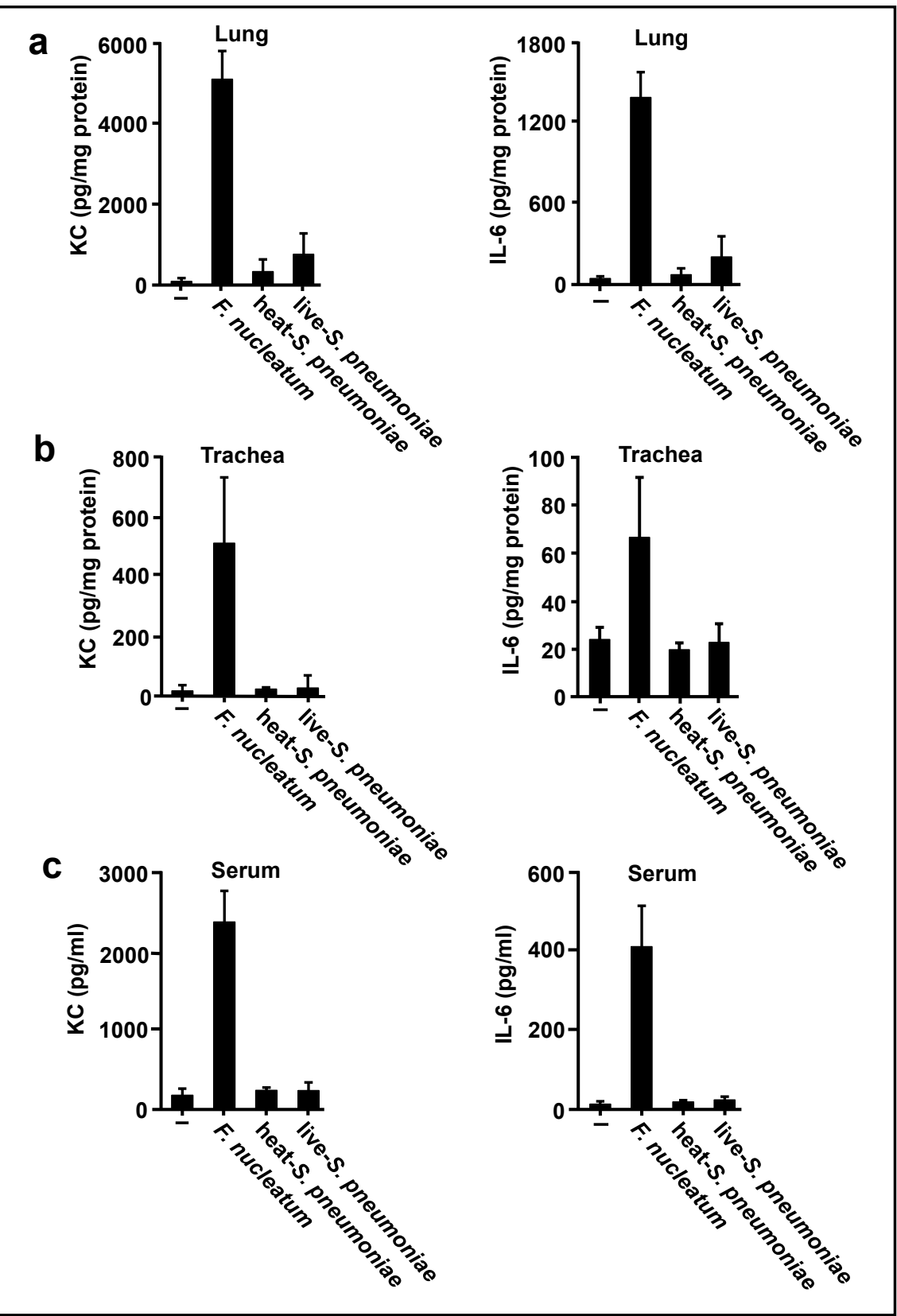

tract compared to the lungs. Furthermore, as shown in Fig. 5c, F. nucleatum introduced into the trachea caused remarkable increases in KC and IL- 6 protein levels in the serum in mice within $2 \mathrm{~h}$, indicating that the bacterium also induced proinflammatory cytokine production in vivo.

\section{Discussion}

As bacteria in the saliva can be aspirated into the lower respiratory tract through the pharynx, many studies have described a positive association between chronic periodontitis and COPD [12-15, 20, 21]. For example, major periodontopathic bacteria, such as $F$. nucleatum and $P$. gingivalis, have been isolated from clinical samples of patients with COPD [16-19]. However, the mechanism by which periodontopathic bacteria are involved in the 


\section{Cellular Physiology Cell Physiol Biochem 2019;53:49-61 \\ \begin{tabular}{ll|l} 
and Biochemistry 10.33594/000000120 & $\begin{array}{l}\text { O } 2019 \text { The Author(s). Published by } \\
\text { Cell Physiol Biochem Press GmbH\&Co. KG }\end{array}$ \\
\cline { 2 - 3 }
\end{tabular} \\ Hayata et al.: F. nucleatum is a Proinflammatory Stimulus to Human Respiratory Epithelial \\ Cells}

pathogenesis of COPD has not been delineated. In contrast, respiratory bacteria such as $S$. pneumoniae induce proinflammatory cytokine production by lower respiratory epithelial cells, which plays a key role in initiating and orchestrating inflammations in patients with COPD by recruiting and activating multiple inflammatory cell types in the lower respiratory tract [5-7]. In this regard, major periodontopathic bacteria also appear to be proinflammatory [1]. Based on these reports, we hypothesize that exposure to increased number of periodontopathic bacteria during aspiration as a result of poor oral hygiene potentially exerts proinflammatory effects on the respiratory epithelium in patients with COPD. However, it is unclear how long these bacteria survive when incubated with human respiratory cells under experimental conditions. Moreover, we were rather interested in inducible effects associated with heat-inactivated periodontopathic bacteria on proinflammatory cytokine production by human respiratory epithelial cells. In addition, surface structures and some biological functions of gram-negative bacteria inactivated by heat are preserved compared with those of live bacteria $[28,29]$. Therefore, we used heat-inactivated bacteria in the present study. We first found that some periodontopathic bacteria, but not all bacteria, function as stimulants to induce IL-8 and IL-6 production by the human bronchial epithelial cell line. Next, we found that among the periodontal bacteria, F. nucleatum alone intensely induced cytokine production by several human respiratory epithelial cell lines, including bronchial and pharyngeal epithelial cells, in a density-dependent manner. Further, F. nucleatum strongly induced cytokine production in the lower respiratory organs in mice. These observations suggest that F. nucleatum, even when devoid of its vitality, is a potent proinflammatory stimulant for the human bronchial and pharyngeal epithelial cells and respiratory organs in mice.

IL-8, a potent neutrophil chemoattractant and activator, has been associated with the pathogenesis of COPD, ascribable to the accumulation and degranulation of neutrophils, which are responsible for the subsequent destruction of normal tissues [7]. Many studies have demonstrated that IL-8 levels are markedly increased in the BALF or induced sputum of patients with COPD and that this induction is correlated with the increased proportion of neutrophils as well as the increased concentration of elastase [7-9, 30]. There is also a significant correlation between IL-8 levels and bacterial infection [9, 31]. Moreover, cultured respiratory epithelial cells from patients with COPD secrete more IL-8 than that secreted by those from normal smokers, indicating an amplified response [32]. Likewise, IL-6 activity is involved in the stimulation of acute-phase protein synthesis, leukocyte recruitment, B-cell differentiation, and T-cell activation in many chronic inflammatory diseases [7]. The IL-6 concentration is also increased in the BALF, induced sputum, and exhaled breath condensate of patients with COPD, particularly during its exacerbations $[7,10,11,33]$. In addition, IL-6 levels increase in the plasma during COPD exacerbations [34]. Our interspecies comparison of cytokine production suggested that $F$. nucleatum is a more potent proinflammatory stimulant in the lower and pharyngeal epithelia of humans than S. pneumoniae. Moreover, proinflammatory cytokines are multifunctional and exert their influences in paracrine and autocrine manners on modulating inflammatory responses of respiratory epithelial cells [57]. Thus, our findings suggest that the inflammation that triggers COPD exacerbation is caused by exposure to $F$. nucleatum and by the absorption of paracrine proinflammatory cytokines released from the pharyngeal epithelium, which is induced by a precedent exposure to $F$. nucleatum. In fact, periodontopathic bacteria are present in high numbers in periodontitis lesions, tongue dorsum, and saliva $[22,35]$. In addition, in patients with COPD, the risk of aspiration has increased because these patients have reduced laryngopharyngeal sensitivity and an increased risk of mild cognitive impairment [24,36], resulting in swallowing reflex impairment [37]. These observations along with our findings may support our hypothesis that an increased number of periodontopathic bacteria in the saliva as a result of poor oral hygiene increases the risk of COPD exacerbation.

Respiratory epithelial cells represent the first line of defense against pathogens that colonize the respiratory tract. In addition, bacteria adhere to respiratory epithelial cells via specific adhesin-receptor interactions. Recognition of bacteria by respiratory epithelial 


\section{Cellular Physiology Cell Physiol Biochem 2019;53:49-61 \begin{tabular}{l|l} 
DOI: 10.33594/000000120 & (c) 2019 The Author(s). Published by \\
Cell Physiol
\end{tabular} \\ Hayata et al.: F. nucleatum is a Proinflammatory Stimulus to Human Respiratory Epithelial Cells}

cells possibly induces the production of proinflammatory cytokines. Similar to other infectious diseases, adhesion to and subsequent invasion of the gingival sulcular epithelium by periodontopathic bacteria are critical steps in the initiation of chronic periodontitis. However, because heat-inactivated bacteria were used to stimulate respiratory epithelial cell lines in the present study, our findings indicate that infection was not necessarily required for the observed induction of proinflammatory cytokine production. In fact, heat-inactivated periodontopathic bacteria, such as F. nucleatum and P. gingivalis, can modulate the expression of proinflammatory cytokines from several types of human cells, such as macrophages, peripheral blood mononuclear cells, and gingival epithelium [38-40]. Additionally, in the lungs and trachea of intratracheally inoculated mice, we found that significantly greater proinflammatory cytokine production was induced by heat-inactivated F. nucleatum than by heat-inactivated or live S. pneumoniae during 2-h incubation, a period during which engulfed live bacteria were not expected to multiply [27]. Interestingly, the observed elevation of proinflammatory cytokines in the serum of $F$. nucleatum-treated mice suggested that these cytokines released from the lower respiratory epithelial cells reached the circulatory system within a short period.

Interactions between the surface molecules of $F$. nucleatum possibly involved in the observed cytokine production in this study, expression of pattern recognition receptors such as Toll-like receptors (TLRs) on the respiratory epithelial cell membrane, and expression of lipopolysaccharide on the outer membrane of $F$. nucleatum are important for the first step of proinflammatory cytokine production [41].

Till date, we have observed that TLR2 is involved in the observed cytokine production (data not shown). Further studies are, therefore, required to identify which bacterial structures and host epithelial receptors are possibly involved in these events. However, our findings suggest that periodontopathic bacteria potentially exacerbate COPD by proinflammatory cytokine production and provide a scientific basis to support the importance of maintaining good oral hygiene.

\section{Acknowledgements}

This work was supported by JSPS KAKENHI, the Dental Research Center, Nihon University School of Dentistry, and the Nihon University Multidisciplinary Research Grant for 2017.

\section{Disclosure Statement}

The authors have no conflicts of interest to declare.

\section{References}

1 Kinane DF, Stathopoulou PG, Papapanou PN: Periodontal diseases. Nat Rev Dis Primers 2017;3:17038.

2 Moore WE, Moore LV: The bacteria of periodontal diseases. Periodontol 2000 1994;5:66-77.

3 Imai K, Ochiai K, Okamoto T: Reactivation of latent HIV-1 infection by the periodontopathic bacterium Porphyromonas gingivalis involves histone modification. J Immunol 2009;182:3688-3695.

4 Imai K, Yamada K, Tamura M, Ochiai K, Okamoto T: Reactivation of latent HIV-1 by a wide variety of butyric acid-producing bacteria. Cell Mol Life Sci 2012;2583-2592.

5 Barnes PJ: The cytokine network in asthma and chronic obstructive pulmonary disease. J Clin Invest 2008;118:3546-3556.

6 Celli BR, Barnes PJ: Exacerbations of chronic obstructive pulmonary disease. Eur Respir J 2007;29:12241238.

7 Barnes PJ: Mediators of chronic obstructive pulmonary disease. Pharmacol Rev 2004;56:515-548. 


\section{Cellular Physiology Cell Physiol Biochem 2019;53:49-61 \begin{tabular}{l|l} 
DOI: 10.33594/000000120 & (c)19 The Author(s). Published by
\end{tabular} and BiOChemistry Published online: 7 June $2019 \quad$ Cell Physiol Biochem Press GmbH\&Co. KG \\ Hayata et al.: F. nucleatum is a Proinflammatory Stimulus to Human Respiratory Epithelial \\ Cells}

8 Aaron SD, Angel JB, Lunau M, Wright K, Fex C, Le Saux N, Dales RE: Granulocyte inflammatory markers and airway infection during acute exacerbation of chronic obstructive pulmonary disease. Am J Respir Crit Care Med 2001;163:349-355.

9 Nocker RE, Schoonbrood DF, van de Graaf EA, Hack CE, Lutter R, Jansen HM, Out TA: Interleukin-8 in airway inflammation in patients with asthma and chronic obstructive pulmonary disease. Int Arch Allergy Immunol 1996;109:183-191.

10 Bhowmik A, Seemungal TA, Sapsford RJ, Wedzicha JA: Relation of sputum inflammatory markers to symptoms and lung function changes in copd exacerbations. Thorax 2000;55:114-120.

11 Song W, Zhao J, Li Z: Interleukin-6 in bronchoalveolar lavage fluid from patients with COPD. Chin Med J 2001;114:1140-1142.

12 Zeng XT, Tu ML, Liu DY, Zheng D, Zhang J, Leng W: Periodontal disease and risk of chronic obstructive pulmonary disease: A meta-analysis of observational studies. PLoS One 2012;7:e46508.

13 Liu Z, Zhang W, Zhang J, Zhou X, Zhang L, Song Y, Wang Z: Oral hygiene, periodontal health and chronic obstructive pulmonary disease exacerbations. J Clin Periodontol 2012;39:45-52.

14 Hayes C, Sparrow D, Cohen M, Vokonas PS, Garcia RI: The association between alveolar bone loss and pulmonary function: The VA Dental Longitudinal Study. Ann Periodontol 1998;3:257-261.

15 Leuckfeld I, Obregon-Whittle MV, Lund MB, Geiran O, Bjortuft O, Olsen I: Severe chronic obstructive pulmonary disease: Association with marginal bone loss in periodontitis. Respir Med 2008;102:488494.

16 Tan L, Wang H, Li C, Pan Y: 16S rDNA-based metagenomic analysis of dental plaque and lung bacteria in patients with severe acute exacerbations of chronic obstructive pulmonary disease. J Periodontal Res 2014;49:760-769.

17 Engel M, Endesfelder D, Schloter-Hai B, Kublik S, Granitsiotis MS, Boschetto P, Stendardo M, Barta I, Dome B, Deleuze JF, Boland A, Müller-Quernheim J, Prasse A, Welte T, Hohlfeld J, Subramanian D, Parr D, Gut IG, Greulich T, Koczulla AR, et al.: Influence of lung CT changes in chronic obstructive pulmonary disease (COPD) on the human lung microbiome. PLoS One 2017;12:e0180859.

18 Erb-Downward JR, Thompson DL, Han MK, Freeman CM, McCloskey L, Schmidt LA, Young VB, Toews GB, Curtis JL, Sundaram B, Martinez FJ, Huffnagle GB: Analysis of the lung microbiome in the "healthy" smoker and in COPD. PLoS One 2011;6:e16384.

19 Bourgault AM, Lamothe F, Dolce P, Saint-Jean L, Saint-Antoine P: Fusobacterium bacteremia: Clinical experience with 40 cases. Clin Infect Dis 1997;25 Suppl 2:S181-183.

20 Kucukcoskun M, Baser U, Oztekin G, Kiyan E, Yalcin F: Initial periodontal treatment for prevention of chronic obstructive pulmonary disease exacerbations. J Periodontol 2013;84:863-870.

21 Zhou X, Han J, Liu Z, Song Y, Wang Z, Sun Z: Effects of periodontal treatment on lung function and exacerbation frequency in patients with chronic obstructive pulmonary disease and chronic periodontitis: A 2-year pilot randomized controlled trial. J Clin Periodontol 2014;41:564-572.

22 Saygun I, Nizam N, Keskiner I, Bal V, Kubar A, Acikel C, Serdar M, Slots J: Salivary infectious agents and periodontal disease status. J Periodontal Res 2011;46:235-239.

23 Marik PE, Kaplan D: Aspiration pneumonia and dysphagia in the elderly. Chest 2003;124:328-336.

24 Clayton NA, Carnaby GD, Peters MJ, Ing AJ: Impaired laryngopharyngeal sensitivity in patients with COPD: The association with swallow function. Int J Speech Lang Pathol 2014;16:615-623.

25 Kamio N, Imai K, Shimizu K, Cueno ME, Tamura M, Saito Y, Ochiai K: Neuraminidase-producing oral mitis group streptococci potentially contribute to influenza viral infection and reduction in antiviral efficacy of zanamivir. Cell Mol Life Sci 2015;72:357-366.

26 Imai K, Kamio N, Cueno ME, Saito Y, Inoue H, Saito I, Ochiai K: Role of the histone H3 lysine 9 methyltransferase Suv39 h1 in maintaining Epsteinn-Barr virus latency in B95-8 cells. FEBS J 2014;281:2148-2158.

27 Ring A, Weiser JN, Tuomanen EI: Pneumococcal trafficking across the blood-brain barrier. Molecular analysis of a novel bidirectional pathway. J Clin Invest 1998;102:347-360.

28 Elson G, Dunn-Siegrist I, Daubeuf B, Pugin J: Contribution of toll-like receptors to the innate immune response to gram-negative and gram-positive bacteria. Blood 2007;109:1574-1583.

29 Hacker H, Furmann C, Wagner H, Hacker G: Caspase-9/-3 activation and apoptosis are induced in mouse macrophages upon ingestion and digestion of Escherichia coli bacteria. J Immunol 2002;169:3172-3179. 


\section{Cellular Physiology Cell Physiol Biochem 2019;53:49-61

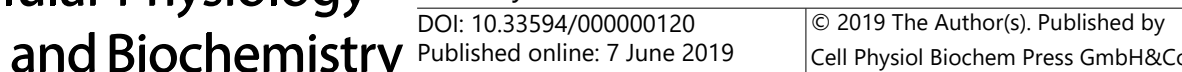 \\ Hayata et al.: F. nucleatum is a Proinflammatory Stimulus to Human Respiratory Epithelial}

30 Soler N, Ewig S, Torres A, Filella X, Gonzalez J, Zaubet A: Airway inflammation and bronchial microbial patterns in patients with stable chronic obstructive pulmonary disease. Eur Respir J 1999;14:10151022.

31 Hill AT, Campbell EJ, Hill SL, Bayley DL, Stockley RA: Association between airway bacterial load and markers of airway inflammation in patients with stable chronic bronchitis. Am J Med 2000;109:288-295.

32 Schulz C, Wolf K, Harth M, Kratzel K, Kunz-Schughart L, Pfeifer M: Expression and release of interleukin-8 by human bronchial epithelial cells from patients with chronic obstructive pulmonary disease, smokers, and never-smokers. Respiration 2003;70:254-261.

33 Bucchioni E, Kharitonov SA, Allegra L, Barnes PJ: High levels of interleukin-6 in the exhaled breath condensate of patients with COPD. Respir Med 2003;97:1299-1302.

34 Wedzicha JA, Seemungal TA, MacCallum PK, Paul EA, Donaldson GC, Bhowmik A, Jeffries DJ, Meade TW: Acute exacerbations of chronic obstructive pulmonary disease are accompanied by elevations of plasma fibrinogen and serum IL-6 levels. Thromb Haemost 2000;84:210-215.

35 Paster BJ, Olsen I, Aas JA, Dewhirst FE: The breadth of bacterial diversity in the human periodontal pocket and other oral sites. Periodontol 2000 2006;42:80-87.

36 Singh B, Mielke MM, Parsaik AK, Cha RH, Roberts RO, Scanlon PD, Geda YE, Christianson TJ, Pankratz VS, Petersen RC: A prospective study of chronic obstructive pulmonary disease and the risk for mild cognitive impairment. JAMA Neurol 2014;71:581-588.

37 Stein M, Williams AJ, Grossman F, Weinberg AS, Zuckerbraun L: Cricopharyngeal dysfunction in chronic obstructive pulmonary disease. Chest 1990;97:347-352.

38 Takahashi N, Honda T, Domon H, Nakajima T, Tabeta K, Yamazaki K: Interleukin-1 receptor-associated kinase-M in gingival epithelial cells attenuates the inflammatory response elicited by Porphyromonas gingivalis. J Periodontal Res 2010;45:512-519.

39 Tietze K, Dalpke A, Morath S, Mutters R, Heeg K, Nonnenmacher C: Differences in innate immune responses upon stimulation with gram-positive and gram-negative bacteria. J Periodontal Res 2006;41:447-454.

40 Jewett A, Hume WR, Le H, Huynh TN, Han YW, Cheng G, Shi W: Induction of apoptotic cell death in peripheral blood mononuclear and polymorphonuclear cells by an oral bacterium, fusobacterium nucleatum. Infect Immun 2000;68:1893-1898.

41 Kawai T, Akira S: The role of pattern-recognition receptors in innate immunity: Update on toll-like receptors. Nat Immunol 2010;11:373-384. 